\title{
"Drinking in the Dark" (DID) Procedures: A Model of Binge-Like Ethanol Drinking in Non-Dependent Mice
}

\author{
Todd E. Thiele ${ }^{1,2}$ and Montserrat Navarro ${ }^{1}$ \\ ${ }^{1}$ Department of Psychology, University of North Carolina at Chapel Hill, Davie Hall, CB \#3270, \\ Chapel Hill, NC 27599-3270, USA \\ ${ }^{2}$ Bowles Center for Alcohol Studies, University of North Carolina at Chapel Hill, Davie Hall, CB \\ \#3270, Chapel Hill, NC 27599-3270, USA
}

\begin{abstract}
This review provides an overview of an animal model of binge-like ethanol drinking that has come to be called "drinking in the dark" (DID), a procedure that promotes high levels of ethanol drinking and pharmacologically relevant blood ethanol concentrations (BECs) in ethanolpreferring strains of mice. Originally described by Rhodes et al. (2005), the most common variation of the DID procedure, using singly housed mice, involves replacing the water bottle with a bottle containing $20 \%$ ethanol for 2 to 4 hours, beginning 3 hours into the dark cycle. Using this procedure, high ethanol drinking strains of mice (e.g., C57BL/6J) typically consume enough ethanol to achieve BECs greater than $100 \mathrm{mg} / \mathrm{dL}$ and to exhibit behavioral evidence of intoxication. This limited access procedure takes advantage of the time in the animal's dark cycle in which the levels of ingestive behaviors are high, yet high ethanol intake does not appear to stem from caloric need. Mice have the choice of drinking or avoiding the ethanol solution, eliminating the stressful conditions that are inherent in other models of binge-like ethanol exposure in which ethanol is administered by the experimenter, and in some cases, potentially painful. The DID procedure is a high throughput approach that does not require extensive training or the inclusion of sweet compounds to motivate high levels of ethanol intake. The high throughput nature of the DID procedure makes it useful for rapid screening of pharmacological targets that are protective against binge-like drinking and for identifying strains of mice that exhibit binge-like drinking behavior. Additionally, the simplicity of DID procedures allows for easy integration into other paradigms, such as prenatal ethanol exposure and adolescent ethanol drinking. It is suggested that the DID model is a useful tool for studying the neurobiology and genetics underlying binge-like ethanol drinking, and may be useful for studying the transition to ethanol dependence.
\end{abstract}

\footnotetext{
(c) 2013 Elsevier Inc. All rights reserved.

Corresponding author: Todd E. Thiele, Ph.D., Department of Psychology, University of North Carolina, Davie Hall, CB \#3270, Chapel Hill, NC 27599-3270, USA, Phone: 919-966-1519, Fax: 919-962-2537, thiele@ unc.edu.

Publisher's Disclaimer: This is a PDF file of an unedited manuscript that has been accepted for publication. As a service to our customers we are providing this early version of the manuscript. The manuscript will undergo copyediting, typesetting, and review of the resulting proof before it is published in its final citable form. Please note that during the production process errors may be discovered which could affect the content, and all legal disclaimers that apply to the journal pertain.
} 


\section{Keywords}

drinking-in-the-dark; binge-like; ethanol; intoxication; blood-ethanol; dependence

For many years, to study the neurobiology of alcoholism, pre-clinical research strategies primarily relied on rodent models that involved voluntary consumption of ethanol, in which rats or mice were given 24-hour/day access to ethanol solutions and water simultaneously in separate bottles. However, voluntary ethanol consumption may not be the most appropriate model for human alcohol abuse disorders, as most rodents typically consume low amounts of ethanol that do not generate blood ethanol concentrations (BECs) thought to be pharmacologically meaningful. Furthermore, alcohol abuse and alcoholism are complex disorders and it is generally accepted that no single animal model will capture all the features of the human condition (Crabbe et al., 2011; Rhodes et al., 2005). Thus, it has been suggested that a more realistic alternative is to develop multiple partial models, each of which is designed to study a subset of the features associated with alcoholism (Rhodes et al., 2005). In recent years, several partial models have been utilized, including those that model excessive ethanol intake stemming from ethanol dependence (Funk et al., 2007; Gilpin et al., 2011; Roberts et al., 1996), excessive relapse-like ethanol drinking resulting from a period of ethanol deprivation (Spanagel \& Holter, 2000; Spanagel et al., 1996; Sparta et al., 2009), and relapse-like ethanol-seeking behaviors triggered by cues previously paired with ethanol, stress, or "priming" doses of ethanol (Lê et al., 1999, 1998; Liu and Weiss, 2002). These models have been useful for discovering the neurochemical pathways and the neurocircuitry modulating dependence-like and relapse-like phenotypes.

However, models of heavy alcohol use and binge alcohol drinking patterns, which can emerge prior to the onset of dependence, have received far less attention. A 'binge' was defined by the National Institute on Alcohol Abuse and Alcoholism (NIAAA) as a pattern of drinking that produces BECs greater than $0.08 \%(80 \mathrm{mg} / \mathrm{dL}$ ) (NIAAA, 2004). The pattern of alcohol drinking required to produce these BECs is about 5 and 4 drinks in 2 hours for the average adult male and female, respectively. The case for understanding the underlying neurobiology of binge ethanol intake can easily be made by highlighting some of the harmful consequences that are associated with this behavioral pattern. While about $90 \%$ of the ethanol consumed by individuals under the age of 21 in the United States is in the form of binge drinking, $70 \%$ of binge drinking episodes in the US involve adults age 26 years and older (Naimi et al., 2003). Thus, binge drinking is not limited to the young but is a risky behavior prevalent in adults. Frequent binge drinking entails numerous negative short- and long-term consequences. Thus, binge drinking has been linked to an increased risk of mood disorders (Okoro et al., 2004), aggressive and violent behavior (Shepherd et al., 2006), and impaired decision making and judgment (Goudriaan et al., 2007). Furthermore, regular binge drinking has been linked to long-term health consequences including heart disease, high blood pressure, and type 2 diabetes (Fan et al., 2008). Perhaps most alarming is the finding of an increased risk for developing alcohol dependence in individuals that binge drink early in life (Hingson et al., 2005; Miller et al., 2007). Thus, it is of paramount importance to identify neurochemical pathways in the brain that modulate binge drinking, as such knowledge may provide insight into novel pharmaceutical treatments that could protect 
against this dangerous behavior. Pharmaceutical targets that are useful for curbing and/or preventing binge drinking could not only help individuals avoid many of the health consequences noted above, but may protect vulnerable individuals from progressing to the point of ethanol dependence. In recent years, several pre-clinical animal models of bingelike ethanol drinking have emerged. These models were designed with the primary goal of establishing procedures that cause animals to achieve pharmacologically relevant BECs in a short period of time. In the case of mice, a criterion of $100 \mathrm{mg} / \mathrm{dL}$ or greater has been suggested because of the high rate of ethanol metabolism in mice (Crabbe et al., 2011). In the present review, we focus on a mouse model of binge-like ethanol drinking originally described by John Crabbe's group (Rhodes et al., 2005) and which has subsequently come to be called the "drinking in the dark" (DID) procedure. While previous investigators have demonstrated that mice drink more ethanol during the dark cycle, a time when mice are most active (Dole \& Gentry, 1984), and have in fact used this knowledge to increase the level of ethanol intake by mice (e.g., [Middaugh et al., 2003; Ryabinin et al., 2003]), Rhodes et al. (2005) have provided the most detailed characterization of the parameters influencing limited-access dark-cycle ethanol consumption in high ethanol drinking C57BL/6J mice.

\section{DID Procedures and Influencing Factors}

Rhodes and colleagues tested a variety of factors that influence the amount of ethanol consumed by mice using variations of the DID procedure. Variations included ethanol concentration, the length of time into the dark cycle that ethanol was offered, the source from which the experimental mice were obtained, and mouse sex and strain (Rhodes et al., 2005). The general DID procedure implemented by Rhodes et al. (2005) was to house C57BL/6J mice (or other strains under consideration) individually and to replace the water bottle with a bottle containing an ethanol solution. Mice were maintained on a 12-hour light, 12-hour dark cycle and mice received limited access to ethanol over 4 consecutive days in most cases. There were no significant differences in the amount of ethanol consumed by C57BL/6J mice $(\mathrm{g} / \mathrm{kg})$ over a 2-hour period when mice were given access to a 10, 20, or $30 \%$ ethanol solution, and $20 \%$ ethanol was chosen for subsequent experiments. Using a paradigm in which mice received 20\% ethanol in place of water for 2 hours over 4 consecutive days, different groups of mice received access to the ethanol solution beginning 1,2 , or 3 hours into the dark cycle. They found that mice drank significantly more ethanol $(4.19 \pm 0.35 \mathrm{~g} / \mathrm{kg})$ and achieved higher BECs $(106 \pm 15 \mathrm{mg} / \mathrm{dL})$ when ethanol was given 3 hours into the dark cycle, relative to initiating ethanol access 1 or 2 hours into the dark cycle. Interestingly, when ethanol access was given over 2 hours on days 1-3 of the procedure but extended to a 4-hour period on day 4, mice drank even greater levels of ethanol $(7.85 \pm 0.38 \mathrm{~g} / \mathrm{kg})$ and achieved higher BECs $(159 \pm 15 \mathrm{mg} / \mathrm{dL})$. An additional study found that delaying the initiation of ethanol access to 4 hours into the dark cycle did not augment ethanol intake beyond what was observed in mice receiving access beginning 3 hours into the dark cycle. Consistent with the literature, they noted that in general, female C57BL/6J mice drank more than male mice, and that the DBA/2J strain of mice $(1.5 \pm 0.43$ $\mathrm{g} / \mathrm{kg})$ drank significantly less ethanol than C57BL/6J mice $(7.5 \pm 0.24 \mathrm{~g} / \mathrm{kg})$, and achieved significantly lower BECs ( $13 \pm 8 \mathrm{mg} / \mathrm{dL}$ versus $140 \pm 12 \mathrm{mg} / \mathrm{dL}$, respectively) after 4 hours of ethanol access. Rhodes et al. (2005) also noted that ethanol consumption was consistent 
within individual mice and reliably predicted BECs, and that the levels of ethanol intake on days 2-4 of the standard 4-day test were significantly correlated with each other, but that consumption on day 1 did not correlate with intake on any other day. This latter observation suggests that at least 1 day of habituation to the procedure is necessary for DID measurements to be reliable.

The highest ethanol consumption and associated BECs were achieved with the DID procedure that used C57BL/6J mice, with 2 hours of $20 \%$ ethanol access on days 1-3 followed by 4 hours of $20 \%$ ethanol access on day 4 (Rhodes et al., 2005). Therefore, this particular variation has been commonly used in experiments investigating the neurobiology of binge-like ethanol drinking (e.g., Giardino \& Ryabinin, in press; Kaur et al., 2012; Lowery-Gionta et al., 2012; Lyons et al., 2008; Sparrow et al., 2012; Sparta et al., 2008). However, other variations of this basic procedure have also been shown to generate reliable levels of ethanol intake and high BECs. For example, Boehm and colleagues (Moore et al., 2010) have used a procedure in which C57BL/6J mice are given 2 hours of access to 20\% ethanol in place of water 3 hours into the dark cycle, for a total of 28 days (with 3 weeks of abstinence between the 14th day and 15th day of ethanol access). BECs measured on days 14 and 28 of the ethanol access showed that adult C57BL/6J mice achieved BECs well above the $100 \mathrm{mg} / \mathrm{dL}$ level (Moore et al., 2010). Further, John Crabbe's group has developed 2 selectively bred, High Drinking in the Dark (HDID) lines of mice using a 2-day variation of the DID procedure in which mice are given access to $20 \%$ ethanol for 2 hours on day 1 and then for 4 hours on day 2. Originally selected from a heterogeneous stock of mice (HS/Npt), HDID mice were tested after 11 generations of selective breeding, and 56\% of the HDID mice drank enough ethanol with this 2-day DID procedure to achieve BECs above $100 \mathrm{mg} / \mathrm{dL}$ (Crabbe et al., 2009). Taken together, the factors associated with the DID procedure that appear to be most important for achieving binge-like levels of ethanol drinking and high BECs are a) the use of a high ethanol drinking line of mice, b) limited access (2-4 hours) to an ethanol solution in place of water, and c) initiation of ethanol access which begins 3 hours into the dark cycle.

In a follow-up study, Rhodes and colleagues asked if concurrent access to a bottle containing water would influence measures observed with DID procedures (Rhodes et al., 2007). Using a panel of 8 different inbred strains of mice, they compared ethanol intake and associated BECs using the 4-day variation of the DID procedure in which mice were given $20 \%$ ethanol with or without concurrent access to a bottle of water. Interestingly, while C57BL/6J mice consumed similar amounts of ethanol with or without water available ( $\sim 6-7$ $\mathrm{g} / \mathrm{kg}), \mathrm{C} 57 \mathrm{BL} / 6 \mathrm{~J}$ mice with concurrent water availability achieved BECs which were on average less than $80 \mathrm{mg} / \mathrm{dL}$, while C57BL/6J mice with access to ethanol alone achieved BECs that were on average greater than $120 \mathrm{mg} / \mathrm{dL}$. Lower BECs when water is available may be related to slower absorption of ethanol in the presence of water in the gastrointestinal tract. At first glance these observations appear to suggest that water availability does not alter the motivation to consume ethanol during DID procedures (i.e., thirst and/or lack of an alternate fluid source may not be a motivating factor for high ethanol drinking). However, mice in this experiment were not ethanol-naïve, and thus potential experimental carry-over effects prevent Rhodes et al. (2007) from firmly eliminating thirst and/or lack of water availability as a motivating factor (this issue is further considered 
below). However, a recent paper showed that C57BL/6J mice achieved BECs of $\sim 100$ $\mathrm{mg} / \mathrm{dL}$ when water was available using a 4-day DID procedure (though mice had prior experience drinking a sucrose solution, again opening the door for a potential experimental carry-over effect on subsequent ethanol intake) (Giardino \& Ryabinin, 2013). These authors argue that the inclusion of water with DID procedures is useful for assessing relative ethanol preference and for providing an additional measure for assessing specificity of experimental manipulations (i.e., pharmacological treatments or genetic manipulations) on ethanol intake. Additionally, Rhodes et al. showed in a follow-up study that C57BL/6J mice exhibit significant behavioral intoxication after 4 hours of binge-like ethanol drinking with the 4day DID procedure, evidenced by a significantly reduced latency to fall during rotarod testing and an increased frequency of foot-slips in a balance beam test, relative to waterdrinking control mice (Rhodes et al., 2007). These observations reinforce the face validity of the DID procedure as a model of human binge alcohol drinking, and replicate a previous study showing that limited access ethanol drinking in C57BL/6J mice was associated with behavioral intoxication (Sharpe et al., 2005).

Because DID procedures involve providing C57BL/6J mice with access to ethanol toward the beginning of the dark cycle, it is possible that increased ethanol drinking may be related to the high level of nocturnal ingestive behavior that is characteristic of mice (Ho and Chin, 1988; Tabarin et al., 2007). In fact, the highest levels of food intake in mice were found to occur during the first 4 hours of their 12-hour dark cycle (Tabarin et al., 2007), the same window of time during which mice are given access to ethanol using DID procedures. Since ethanol contains calories, this raises the possibility that increased ethanol drinking associated with DID procedures results from presenting ethanol during a time of high caloric need, rather than an increased motivation to drink ethanol for its post-ingestive pharmacological effects. To address this concern, we performed a series of experiments designed to manipulate caloric need in C57BL/6J mice exposed to DID procedures (Lyons et al., 2008). In one experiment, mice were food-deprived between 0 and 10 hours before and during DID procedures. We reasoned that if ethanol were the only source of calories during DID procedures, ethanol intake would be increased relative to mice with free access to food if the caloric need hypothesis is correct. However, food deprivation failed to alter the level of binge-like ethanol drinking or associated BECs. Furthermore, peripheral administration of ghrelin, an orexigenic gut peptide (Wang et al., 2002), or leptin, an anorectic protein synthesized in adipose tissue (Prpic et al., 2003), failed to influence bingelike ethanol drinking with DID procedures in doses that increased or decreased food intake, respectively. Interestingly, although we did not discuss this point previously (Lyons et al., 2008), the observation that mice with varying amounts of food deprivation did not exhibit lower levels of binge-like ethanol drinking relative to mice with ad libitum access to food also makes a strong case against the idea that high ethanol intake (in the absence of water availability) stems from postprandial (feeding-induced) thirst. Taken together, these data are inconsistent with the hypotheses that increased ethanol drinking stemming from DID procedures results from increased caloric need from food deprivation or thirst resulting from eating food, and reinforce the idea that mice exhibit binge-like ethanol drinking with DID procedures for the post-ingestive pharmacological effects of ethanol. 


\section{The Advantages of DID Procedures in Modeling Binge-Like Ethanol Drinking}

One of the clear advantages of DID is that it promotes pharmacologically meaningful BECs in an experimenter-defined limited access time frame (Crabbe et al., 2011). Because ethanol access is limited to a relatively short period of time, one can more easily assess the effects of pharmacological compounds on binge-like ethanol intake, especially in cases where the actions of a drug are short-term (i.e., 4 hours or less). Further, as noted above, mice exhibit behavioral intoxication with DID and similar dark cycle drinking procedures (Rhodes et al., 2007; Sharpe et al., 2005). DID procedures do not require the inclusion of sweet compounds to motivate high levels of ethanol intake. Numerous examples of how DID procedures were employed in pharmacological experiments have been reviewed elsewhere (Sprow \& Thiele, 2012). DID procedures have also been useful for assessing the effects of binge-like ethanol drinking on central neurochemical activity (e.g., Lowery-Gionta et al., 2012; Sparrow et al., 2012).

Perhaps one of the most salient advantages of the DID procedure is its high face validity in terms of a model of human binge drinking, because mice exhibit binge-like drinking under conditions of short-term oral ethanol intake. With other binge models, ethanol is administered by the experimenter, such as by injection, gavage, or ethanol vapor exposure (e.g., Bake et al., 2012; Becker \& Lopez, 2004; Criado et al., 2011; Gilliam \& Kotch, 1996; Pandey et al., 2008), or animals are forced to consume ethanol by long-term fluid deprivation or by including ethanol in a diet that is the sole source of nutrients (e.g., Cozzoli et al., 2009; Roy \& Pandey, 2002; Szumlinski et al., 2005), making their motivation to drink ethanol questionable. Additionally, it is difficult to keep constant the pattern and amount of ethanol consumed between animals using ethanol diet approaches. Most important, these passive, forced, and potentially painful methods of administering ethanol may introduce confounding variables in measurements under consideration.

The DID procedure was originally designed as a high throughput approach useful for screening pharmacological targets that are protective against binge-like drinking and identifying strains of mice that exhibit binge-like drinking (Rhodes et al., 2005). As noted above, DID procedures are successful in promoting binge-like levels of ethanol intake with as little as 2 to 4 hours of ethanol access per day and with as little as 2 days of training. The simple and high throughput design of the DID procedure makes it ideally suited for inclusion with other sophisticated techniques, such as studies involving optogenetic manipulations, chronic indwelling catheters for administration of drugs or collection of blood samples, or in vivo electrophysiological measures.

As a means of illustrating the usefulness of DID procedures, it is of interest to highlight examples of how DID procedures have been successfully utilized to study neurobiological responses resulting from prenatal ethanol exposure and voluntary binge-like ethanol drinking in adolescent mice. Prenatal ethanol exposure in animal models typically involves involuntary procedures such as gavage or injection (Bake et al., 2012; Gilliam \& Kotch, 1996), which as noted above can entail confounding stressful effects. Recently, Boehm and colleagues provided female C57BL/6J mice with $20 \%$ ethanol during pregnancy. They 
drank on average 4.2 to $6.4 \mathrm{~g} / \mathrm{kg}$ of ethanol and achieved average BECs of 115 to 182 $\mathrm{mg} / \mathrm{dL}$. Interestingly, the offspring of ethanol-drinking dams showed reduced sensitivity to ethanol-induced sedation at postnatal day (PND) 31 but not PND 91 (Boehm et al., 2008).

The adolescent period in mouse development is rather short, estimated to be between PND 28-42 (Spear, 2000). Thus, little time is available to accommodate binge-like drinking procedures that require extensive habituation or training. The simple and high throughput design of DID procedures has a clear advantage to studying binge-like ethanol drinking in mice during the adolescent period, and several studies have already taken advantage of DID procedures to study binge-like ethanol drinking in adolescent mice. For example, it was demonstrated that adolescent C57BL/6J mice exhibited higher levels of binge-like ethanol drinking relative to adult mice, and that adolescent mice were less sensitive to ethanolinduced conditioned taste aversions, suggesting that greater binge-like ethanol drinking by adolescent mice may be related to their reduced sensitivity to the aversive effects of ethanol (Holstein et al., 2011). Additionally, adolescent binge-like ethanol drinking has been shown to promote increased ethanol intake that lasts into adulthood in C57BL/6J (Moore et al., 2010) and HS/Npt mice (Metten et al., 2011).

\section{Considerations for the DID Model}

While there are clear advantages to the DID procedure relative to other models of binge-like ethanol consumption/exposure, there are potential limitations with the model which should be considered. As noted above, the DID procedure takes advantage of a time in the animal's circadian rhythm associated with high levels of ingestive behavior. Clearly, administration of ethanol within the animal's dark cycle is a key component to the high level of ethanol intake associated with DID procedures. In fact, we have noted that when C57BL/6J mice were given access to $20 \%$ ethanol beginning 3 hours into the light cycle using DID-like procedures, consumption of ethanol was less than $2 \mathrm{~g} / \mathrm{kg}$ during 4 hours, and associated BECs were less than $20 \mathrm{mg} / \mathrm{dL}$ (Lowery-Gionta et al., 2012). However, it is well recognized that there are circadian fluctuations in neurophysiological activity, including in neurochemical systems within the central nervous system that have been implicated in binge-like ethanol drinking (Mitchell et al., 1998; Sprow \& Thiele, 2012; Vidal \& Lugo, 2006). Thus, studies aimed at understanding the neurobiology of binge-like ethanol drinking utilizing DID procedures may yield results that are specific to the portion of the dark cycle in which measures were collected. Assessing neurobiological responses to ethanol over the course of the light:dark cycle may help shed light on this potential factor (though alternate procedures, such as experimenter administration of ethanol, may be necessary as mice drink less ethanol during the light phase).

Another concern, also related to the timing of ethanol access, is the potential impact of binge-like ethanol drinking on food intake and body weight. Since mice consume binge-like levels of ethanol to the point of intoxication during the time of day that they also consume most of their food, it is possible that DID procedures may interfere with normal feeding patterns, potentially compromising nutritional balance. This issue may be more salient in experiments involving repeated use of DID procedures over days or weeks. Though shortterm food restriction did not alter the level of binge-like ethanol drinking with DID 
procedures (Lyons et al., 2008), it is feasible that more chronic perturbations in energy balance stemming from long-term/repeated DID procedures could impact ethanol intake, as well as any neurobiological measures under consideration. Thus, it may be prudent to carefully track feeding and body weight if long-term DID procedures are employed.

Successful DID procedures (i.e., the ability of DID to motivate ethanol drinking to levels that can promote BECs of $100 \mathrm{mg} / \mathrm{dL}$ or greater) appear to be relatively mouse strain specific, and require the use of mice that exhibit high ethanol preference. Rhodes and colleagues used DID procedures with a panel of 12 inbred strains of mice (Rhodes et al., 2007). Of these strains, only C57BL/6J mice achieved BECs above $100 \mathrm{mg} / \mathrm{dL}$. Thus, the generalizability of observations generated with DID procedures to other strains or species may be somewhat limited. In this regard, it will be important to compare findings from mouse DID experiments with those obtained from a rat model of binge-like ethanol drinking (see the article by Richard Bell in this issue). It is important to note that there is another strain of mice that exhibits binge-like levels of ethanol intake. It was discovered that an F1 hybrid cross between C57BL/6J and FVB/NJ inbred mouse strains consumes more ethanol than either progenitor strain (Blednov et al., 2005), and this hybrid strain exhibits robust binge-like ethanol drinking with the DID procedure (Phillips et al., 2010).

The importance of selection of mouse background strain must also be kept in mind when applying DID procedures to transgenic and knockout mouse models. In many cases, genetically engineered mouse models are created on a background that will drink little to moderate amounts of ethanol. For example, embryonic stem cells from substrains of 129 mice are commonly used in creating gene knockout mice, and these mice are then bred with C57BL/6 mice to yield a hybrid (Gerlai, 1996, 2001). However, 129 substrain mice drink modest amounts of ethanol (Belknap et al., 1993) and fail to exhibit binge-like levels of ethanol intake or associated BECs with DID procedures (Rhodes et al., 2007). This potential limitation may be overcome by backcrossing the transgenic or knockout model onto a C57BL/6 background over multiple generations to yield mice that are on a nearly $100 \%$ C57BL/6 genetic background. For example, we backcrossed a mutant mouse lacking normal production of agouti-related protein (AgRP) to a C57BL/6J background for 8 generations, and found that while littermate wild-type AgRP+/+ mice drank enough ethanol to achieve BECs greater than $120 \mathrm{mg} / \mathrm{dL}$ over a 4-hour DID test, AgRP-/- mice drank less ethanol and achieved BECs of around $80 \mathrm{mg} / \mathrm{dL}$ (Navarro et al., 2009). Similarly, Kaur et al. backcrossed mutant mice lacking corticotropin releasing factor (CRF) or CRF receptors to a C57BL/6 background for at least 8 generations and were successful in obtaining binge-like ethanol drinking in these mice using DID procedures (Kaur et al., 2012).

It might be argued that high ethanol drinking with DID procedures stems from a change in the taste reactivity to ethanol over the 2-4 days of ethanol access. Specifically, C57BL/6J mice might develop reduced sensitivity to the aversive taste components of ethanol and thus be willing to consume more ethanol. While this argument cannot be completely ruled out, there is evidence that is contrary to this hypothesis. First, C57BL/6J mice show relatively stable ethanol intake over the 4-day DID procedure (Rhodes et al., 2005). Additionally, if mice develop reduced sensitivity to the aversive taste components of ethanol and this contributes to increased binge-like ethanol intake, one would predict that binge-like ethanol 
drinking would gradually increase over the course of repeated DID procedures. However, we recently reported that while repeated episodes of DID promoted significant increases of subsequent 24-hour, 2-bottle voluntary ethanol intake, the level of binge-like ethanol drinking did not increase, even after up to 10, 4-day DID episodes (Cox et al., in press).

One final potential limitation that may be present in the DID procedure is that with the typical DID protocol, the water bottle is removed from the animal's cage over the 2- to 4hour test. Thus, no choice for an alternate source of fluid is offered, raising the possibility that the high levels of ethanol intake with DID procedures stems from the mice being forced to choose between ethanol consumption or thirst resulting from fluid deprivation. However, it has previously been argued that mice are not forced to drink ethanol over this short period of water deprivation (Crabbe et al., 2011), because mice can choose not to drink ethanol at all, and in fact many genotypes drink very little ethanol solution in the DID test (Rhodes et al., 2007). Further, as discussed above, high ethanol intake with DID procedures is probably not caused by postprandial thirst stemming from feeding (Lyons et al., 2008). Taken together, it would appear unlikely that the high ethanol intake stemming from DID procedures results from the lack of an alternative fluid choice that would prevent thirst. However, this is still an unresolved issue that requires additional investigation.

\section{Future Directions with DID Procedures}

Additional research is needed to a) further characterize and potentially improve DID procedures, $b$ ) understand the neurobiology and mechanisms that modulate binge-like ethanol drinking with DID procedures, and c) discover ways to expand the utility of the DID procedure. As noted above, much has been done to characterize the factors that influence the level of binge-like ethanol drinking with DID procedures. Thus, providing $20 \%$ ethanol in place of water for 2 to 4 hours beginning 3 hours into the dark cycle and the use of high drinking strains of mice such as the C57BL/6 strain appear to be the most important factors (Rhodes et al., 2005, 2007). Additionally, the pattern of ethanol drinking during DID procedures has been described (Barkley-Levenson \& Crabbe, 2012). Rhodes et al. varied the time that ethanol was offered, up to 4 hours into the dark cycle (Rhodes et al., 2005), and it would be of interest to assess start times over the remainder of the dark cycle. It might also be of interest to determine if there are ways to further increase the level or likelihood of binge-like ethanol drinking, while at the same time maintaining the simple and high throughput approach. One possibility might be to combine DID procedures with other techniques known to achieve increased ethanol intake. For example, Ryabinin and colleagues included sucrose in an ethanol solution as a means of increasing limited-access dark-cycle drinking in C57BL/6J mice (Ryabinin et al., 2003). Interestingly, including a glucose + saccharin mixture to ethanol, often referred to as "supersac," has been shown to induce binge-like ethanol drinking in rats (Ji et al., 2008). Combining sucrose or the supersac mixture with ethanol during DID procedures may further enhance binge-like drinking and associated BECs, particularly when -strains of mice that are more moderate in their ethanol consumption are studied. Additionally, offering multiple bottles of ethanol (e.g., one containing $10 \%$ ethanol and a second containing $20 \%$ ethanol) has been shown to induce higher levels of ethanol intake in mice relative to mice that are given a single bottle of ethanol (Tordoff \& Bachmanov, 2003), and an interesting possibility is that a multiple- 
bottle DID procedure may further enhance the level or likelihood of binge-like drinking and associated BECs.

The neurobiological mechanisms that modulate binge-like ethanol drinking stemming from DID procedures are not well understood and additional investigation is required. Numerous neurochemicals have already been linked to binge-like ethanol drinking (see Sprow \& Thiele, 2012 for a review). It will be important to discover the neurocircuitry and systems that are involved, what mechanisms are involved in the initiation and maintenance of bingelike drinking, and what genetic factors promote binge-like ethanol drinking in some strains but protect other stains from engaging in this behavior. It will also be important to continually compare the results yielded from pre-clinical studies with DID procedures to studies on human binge drinkers as a means of continued evaluation of the validity of this model.

In studying the neurobiology of binge-like ethanol drinking, we have begun to ask if DID procedures may also be useful for studying the neurobiology underlying the transition to ethanol dependence (Thiele, 2012). The striking similarity between results obtained with models of binge-like ethanol drinking in "non-dependent" animals (Lowery-Gionta et al., 2012; Sparrow et al., 2012) and with models of dependence-like ethanol intake (Gilpin et al., 2011; Roberto et al., 2010), with respect to neuroplasticity within the extended amygdala CRF neurocircuitry, suggests the possibility that overlapping systems may be involved. Theoretically, binge-like ethanol drinking with DID procedures may be modulated by transient changes in central neurochemical systems that arise from high BECs. We speculate that such changes are initially transient, but with repeated episodes of binge-like drinking, these neuroplastic changes may become rigid, contributing to excessive dependence-like drinking. Thus, by employing repeated episodes of DID ethanol access, it might be possible to study the neurobiology underlying the transition to ethanol dependence. Reinforcing this idea, as noted above we recently found that a history of repeated DID episodes promoted subsequent increases of voluntary ethanol consumption (Cox et al., in press), an outcome that is also observed in models of ethanol dependence (e.g., chronic intermittent ethanol vapor exposure [Becker \& Lopez, 2004]).

In summary, the DID procedure is an animal model of binge-like ethanol drinking that promotes high levels of ethanol drinking and pharmacologically relevant BECs in ethanolpreferring strains of mice. This limited access procedure takes advantage of the time in the animal's dark cycle in which ingestive behaviors are high, yet high ethanol intake does not appear to stem from caloric need. Mice exhibit binge-like drinking under conditions of short-term oral ethanol intake, eliminating the stressful and potentially painful effects associated with binge models that require experimenter-administered ethanol. The DID procedure is a high throughput approach that is useful for screening pharmacological targets that are protective against binge-like drinking and identifying strains of mice that exhibit binge-like drinking. DID is an ideal tool for studying the neurobiology and genetics underlying binge-like ethanol drinking, and may be useful for studying the transition to ethanol dependence. 


\section{Acknowledgments}

This work was supported by National Institute of Health grants AA022048, AA013573, and AA015148.

\section{References}

Bake S, Tingling JD, Miranda RC. Ethanol exposure during pregnancy persistently attenuates cranially directed blood flow in the developing fetus: evidence from ultrasound imaging in a murine second trimester equivalent model. Alcoholism: Clinical and Experimental Research. 2012; 36:748-758.

Barkley-Levenson AM, Crabbe JC. Ethanol drinking microstructure of a high drinking in the dark selected mouse line. Alcoholism: Clinical and Experimental Research. 2012; 36:1330-1339.

Becker HC, Lopez MF. Increased ethanol drinking after repeated chronic ethanol exposure and withdrawal experience in C57BL/6 mice. Alcoholism: Clinical and Experimental Research. 2004; 28:1829-1838.

Belknap JK, Crabbe JC, Young ER. Voluntary consumption of ethanol in 15 inbred mouse strains. Psychopharmacology. 1993; 112:503-510. [PubMed: 7871064]

Blednov YA, Metten P, Finn DA, Rhodes JS, Bergeson SE, Harris RA, Crabbe JC. Hybrid C57BL/6J $\mathrm{x}$ FVB/NJ mice drink more alcohol than do C57BL/6J mice. Alcoholism: Clinical and Experimental Research. 2005; 29:1949-1958.

Boehm SL 2nd, Moore EM, Walsh CD, Gross CD, Cavelli AM, Gigante E, Linsenbardt DN. Using drinking in the dark to model prenatal binge-like exposure to ethanol in C57BL/6J mice. Developmental Psychobiology. 2008; 50:566-578. [PubMed: 18683190]

Cox BR, Olney JJ, Lowery-Gionta EG, Sprow GM, Rinker RA, Navarro M, Kash TL, Thiele TE. Repeated cycles of binge-like ethanol (EtOH)-drinking in male C57BL/6 J mice augments subsquent voluntary EtOH intake but not other dependence-like phenotypes. Alcoholism: Clinical and Experimental Research. (in press). (Epub ahead of print).

Cozzoli DK, Goulding SP, Zhang PW, Xiao B, Hu JH, Ary AW, Obara I, Rahn A, Abou-Ziab H, Tyrrel B, et al. Binge drinking upregulates accumbens mGluR5-Homer2-PI3K signaling: functional implications for alcoholism. The Journal of Neuroscience. 2009; 29:8655-8668. [PubMed: 19587272]

Crabbe JC, Harris RA, Koob GF. Preclinical studies of alcohol binge drinking. Annals of the New York Academy of Sciences. 2011; 1216:24-40. [PubMed: 21272009]

Crabbe JC, Metten P, Rhodes JS, Yu CH, Brown LL, Phillips TJ, Finn DA. A line of mice selected for high blood ethanol concentrations shows drinking in the dark to intoxication. Biological Psychiatry. 2009; 65:662-670. [PubMed: 19095222]

Criado JR, Liu T, Ehlers CL, Mathé AA. Prolonged chronic ethanol exposure alters neuropeptide Y and corticotropin-releasing factor levels in the brain of adult Wistar rats. Pharmacology, Biochemistry, and Behavior. 2011; 99:104-111.

Dole VP, Gentry RT. Toward an analogue of alcoholism in mice: scale factors in the model. Proceedings of the National Academy of Sciences of the United States of America. 1984; 81:3543-3546. [PubMed: 6587369]

Fan AZ, Russell M, Stranges S, Dorn J, Trevisan M. Association of lifetime alcohol drinking trajectories with cardiometabolic risk. The Journal of Clinical Endocrinology and Metabolism. 2008; 93:154-161. [PubMed: 18029458]

Funk CK, Zorrilla EP, Lee MJ, Rice KC, Koob GF. Corticotropin-releasing factor 1 antagonists selectively reduce ethanol self-administration in ethanol-dependent rats. Biological Psychiatry. 2007; 61:78-86. [PubMed: 16876134]

Gerlai R. Gene-targeting studies of mammalian behavior: is it the mutation or the background genotype? Trends in Neurosciences. 1996; 19:177-181. [PubMed: 8723200]

Gerlai R. Gene targeting: technical confounds and potential solutions in behavioral brain research. Behavioural Brain Research. 2001; 125:13-21. [PubMed: 11682088]

Giardino WJ, Ryabinin AE. CRF1 receptor signaling regulates food and fluid intake in the drinking-inthe-dark model of binge alcohol consumption. Alcoholism: Clinical and Experimental Research. 2013; 37:1161-1170. 
Gilliam DM, Kotch LE. Dose-related growth deficits in LS but not SS mice prenatally exposed to alcohol. Alcohol. 1996; 13:47-51. [PubMed: 8837934]

Gilpin NW, Misra K, Herman MA, Cruz MT, Koob GF, Roberto M. Neuropeptide Y opposes alcohol effects on gamma-aminobutyric acid release in amygdala and blocks the transition to alcohol dependence. Biological Psychiatry. 2011; 69:1091-1099. [PubMed: 21459365]

Goudriaan AE, Grekin ER, Sher KJ. Decision making and binge drinking: a longitudinal study. Alcoholism: Clinical and Experimental Research. 2007; 31:928-938.

Hingson R, Heeren T, Winter M, Wechsler H. Magnitude of alcohol-related mortality and morbidity among U.S. college students ages 18-24: changes from 1998 to 2001. Annual Review of Public Health. 2005; 26:259-279.

Ho A, Chin A. Circadian feeding and drinking patterns of genetically obese mice fed solid chow diet. Physiology \& Behavior. 1988; 43:651-656. [PubMed: 3200922]

Holstein SE, Spanos M, Hodge CW. Adolescent C57BL/6J mice show elevated alcohol intake, but reduced taste aversion, as compared to adult mice: a potential behavioral mechanism for binge drinking. Alcoholism: Clinical and Experimental Research. 2011; 35:1842-1851.

Ji D, Gilpin NW, Richardson HN, Rivier CL, Koob GF. Effects of naltrexone, duloxetine, and a corticotropin-releasing factor type 1 receptor antagonist on binge-like alcohol drinking in rats. Behavioural Pharmacology. 2008; 19:1-12. [PubMed: 18195589]

Kaur S, Li J, Stenzel-Poore MP, Ryabinin AE. Corticotropin-releasing factor acting on corticotropinreleasing factor receptor type 1 is critical for binge alcohol drinking in mice. Alcoholism: Clinical and Experimental Research. 2012; 36:369-376.

Lê AD, Poulos CX, Harding S, Watchus J, Juzytsch W, Shaham Y. Effects of naltrexone and fluoxetine on alcohol self-administration and reinstatement of alcohol seeking induced by priming injections of alcohol and exposure to stress. Neuropsychopharmacology. 1999; 21:435-444. [PubMed: 10457541]

Lê AD, Quan B, Juzytch W, Fletcher PJ, Joharchi N, Shaham Y. Reinstatement of alcohol-seeking by priming injections of alcohol and exposure to stress in rats. Psychopharmacology. 1998; 135:169174. [PubMed: 9497022]

Liu X, Weiss F. Additive effect of stress and drug cues on reinstatement of ethanol seeking: exacerbation by history of dependence and role of concurrent activation of corticotropin-releasing factor and opioid mechanisms. The Journal of Neuroscience. 2002; 22:7856-7861. [PubMed: 12223538]

Lowery-Gionta EG, Navarro M, Li C, Pleil KE, Rinker JA, Cox BR, Sprow GM, Kash TL, Thiele TE. Corticotropin releasing factor signaling in the central amygdala is recruited during binge-like ethanol consumption in C57BL/6J mice. The Journal of Neuroscience. 2012; 32:3405-3413. [PubMed: 22399763]

Lyons AM, Lowery EG, Sparta DR, Thiele TE. Effects of food availability and administration of orexigenic and anorectic agents on elevated ethanol drinking associated with drinking in the dark procedures. Alcoholism: Clinical and Experimental Research. 2008; 32:1962-1968.

Metten P, Brown LL, Crabbe JC. Limited access ethanol drinking in the dark in adolescent and adult mice. Pharmacology, Biochemistry, and Behavior. 2011; 98:279-285.

Middaugh LD, Szumlinski KK, Van Patten Y, Marlowe AL, Kalivas PW. Chronic ethanol consumption by C57BL/6 mice promotes tolerance to its interoceptive cues and increases extracellular dopamine, an effect blocked by naltrexone. Alcoholism: Clinical and Experimental Research. 2003; 27:1892-1900.

Miller JW, Naimi TS, Brewer RD, Jones SE. Binge drinking and associated health risk behaviors among high school students. Pediatrics. 2007; 119:76-85. [PubMed: 17200273]

Mitchell V, Prévot V, Beauvillain JC. Distribution and diurnal variations of the mu opioid receptor expression in the arcuate nucleus of the male rat. Neuroendocrinology. 1998; 67:94-100. [PubMed: 9508039]

Moore EM, Mariani JN, Linsenbardt DN, Melón LC, Boehm SL 2nd. Adolescent C57BL/6J (but not $\mathrm{DBA} / 2 \mathrm{~J})$ mice consume greater amounts of limited-access ethanol compared to adults and display continued elevated ethanol intake into adulthood. Alcoholism: Clinical and Experimental Research. 2010; 34:734-742. 
Naimi TS, Brewer RD, Mokdad A, Denny C, Serdula MK, Marks JS. Binge drinking among US adults. The Journal of the American Medical Association. 2003; 289:70-75.

Navarro M, Cubero I, Ko L, Thiele TE. Deletion of agouti-related protein blunts ethanol selfadministration and binge-like drinking in mice. Genes, Brain, and Behavior. 2009; 8:450-458.

NIAAA. National Institute on Alcohol Abuse and Alcoholism Council approves definition of binge drinking. Winter 2004 NIAAA Newsletter. 2004; 3

Okoro CA, Brewer RD, Naimi TS, Moriarty DG, Giles WH, Mokdad AH. Binge drinking and healthrelated quality of life: do popular perceptions match reality? American Journal of Preventive Medicine. 2004; 26:230-233. [PubMed: 15026103]

Pandey SC, Ugale R, Zhang H, Tang L, Prakash A. Brain chromatin remodeling: a novel mechanism of alcoholism. The Journal of Neuroscience. 2008; 28:3729-3737. [PubMed: 18385331]

Phillips TJ, Reed C, Burkhart-Kasch S, Li N, Hitzemann R, Yu CH, Brown LL, Helms ML, Crabbe JC, Belknap JK. A method for mapping intralocus interactions influencing excessive alcohol drinking. Mammalian Genome. 2010; 21:39-51. [PubMed: 20033183]

Prpic V, Watson PM, Frampton IC, Sabol MA, Jezek GE, Gettys TW. Differential mechanisms and development of leptin resistance in $\mathrm{A} / \mathrm{J}$ versus C57BL/6J mice during diet-induced obesity. Endocrinology. 2003; 144:1155-1163. [PubMed: 12639896]

Rhodes JS, Best K, Belknap JK, Finn DA, Crabbe JC. Evaluation of a simple model of ethanol drinking to intoxication in C57BL/6J mice. Physiology \& Behavior. 2005; 84:53-63. [PubMed: 15642607]

Rhodes JS, Ford MM, Yu CH, Brown LL, Finn DA, Garland T Jr, Crabbe JC. Mouse inbred strain differences in ethanol drinking to intoxication. Genes, Brain, and Behavior. 2007; 6:1-18.

Roberto M, Cruz MT, Gilpin NW, Sabino V, Schweitzer P, Bajo M, Cottone P, Madamba SG, Stouffer DG, Zorrilla EP, et al. Corticotropin releasing factor-induced amygdala gamma-aminobutyric Acid release plays a key role in alcohol dependence. Biological Psychiatry. 2010; 67:831-839. [PubMed: 20060104]

Roberts AJ, Cole M, Koob GF. Intra-amygdala muscimol decreases operant ethanol selfadministration in dependent rats. Alcoholism: Clinical and Experimental Research. 1996; 20:1289-1298.

Roy A, Pandey SC. The decreased cellular expression of neuropeptide Y protein in rat brain structures during ethanol withdrawal after chronic ethanol exposure. Alcoholism: Clinical and Experimental Research. 2002; 26:796-803.

Ryabinin AE, Galvan-Rosas A, Bachtell RK, Risinger FO. High alcohol/sucrose consumption during dark circadian phase in C57BL/6J mice: involvement of hippocampus, lateral septum and urocortin-positive cells of the Edinger-Westphal nucleus. Psychopharmacology. 2003; 165:296305. [PubMed: 12442202]

Sharpe AL, Tsivkovskaia NO, Ryabinin AE. Ataxia and c-Fos expression in mice drinking ethanol in a limited access session. Alcoholism: Clinical and Experimental Research. 2005; 29:1419-1426.

Shepherd JP, Sutherland I, Newcombe RG. Relations between alcohol, violence and victimization in adolescence. Journal of Adolescence. 2006; 29:539-553. [PubMed: 16863892]

Spanagel R, Hölter SM. Pharmacological validation of a new animal model of alcoholism. Journal of Neural Transmission. 2000; 107:669-680. [PubMed: 10943907]

Spanagel R, Hölter SM, Allingham K, Landgraf R, Zieglgänsberger W. Acamprosate and alcohol: I. Effects on alcohol intake following alcohol deprivation in the rat. European Journal of Pharmacology. 1996; 305:39-44. [PubMed: 8813529]

Sparrow AM, Lowery-Gionta EG, Pleil KE, Li C, Sprow GM, Cox BR, Rinker JA, Jijon AM, Peňa J, Navarro M, et al. Central neuropeptide Y modulates binge-like ethanol drinking in C57BL/6J mice via Y1 and Y2 receptors. Neuropsychopharmacology. 2012; 37:1409-1421. [PubMed: 22218088]

Sparta DR, Ferraro FM, Fee JR 3rd, Knapp DJ, Breese GR, Thiele TE. The alcohol deprivation effect in C57BL/6J mice is observed using operant self-administration procedures and is modulated by CRF-1 receptor signaling. Alcoholism: Clinical and Experimental Research. 2009; 33:31-42.

Sparta DR, Sparrow AM, Lowery EG, Fee JR, Knapp DJ, Thiele TE. Blockade of the corticotropin releasing factor type 1 receptor attenuates elevated ethanol drinking associated with drinking in the dark procedures. Alcoholism: Clinical and Experimental Research. 2008; 32:259-265. 
Spear L. Modeling adolescent development and alcohol use in animals. Alcohol Research \& Health. 2000; 24:115-123. [PubMed: 11199278]

Sprow GM, Thiele TE. The neurobiology of binge-like ethanol drinking: evidence from rodent models. Physiology and Behavior. 2012; 106:325-331. [PubMed: 22245775]

Szumlinski KK, Lominac KD, Oleson EB, Walker JK, Mason A, Dehoff MH, Klugman M, Cagle S, Welt K, During M, et al. Homer2 is necessary for EtOH-induced neuroplasticity. The Journal of Neuroscience. 2005; 25:7054-7061. [PubMed: 16049182]

Tabarin A, Diz-Chaves Y, Consoli D, Monsaingeon M, Bale TL, Culler MD, Datta R, Drago F, Vale WW, Koob GF, et al. Role of the corticotropin-releasing factor receptor type 2 in the control of food intake in mice: a meal pattern analysis. The European Journal of Neuroscience. 2007; 26:2303-2314. [PubMed: 17953621]

Thiele TE. Commentary: studies on binge-like ethanol drinking may help to identify the neurobiological mechanisms underlying the transition to dependence. Alcoholism: Clinical and Experimental Research. 2012; 36:193-196.

Tordoff MG, Bachmanov AA. Influence of the number of alcohol and water bottles on murine alcohol intake. Alcoholism: Clinical and Experimental Research. 2003; 27:600-606.

Vidal L, Lugo N. Changes in neuropeptide Y immunoreactivity and transcript levels in circadian system structures of the diurnal rodent, the thirteen-lined ground squirrel. Brain Research. 2006; 1125:77-84. [PubMed: 17109825]

Wang L, Saint-Pierre DH, Taché Y. Peripheral ghrelin selectively increases Fos expression in neuropeptide $\mathrm{Y}$ - synthesizing neurons in mouse hypothalamic arcuate nucleus. Neuroscience Letters. 2002; 325:47-51. [PubMed: 12023064] 